\title{
MUCOPOLYSACCHARIDOSIS
}

\section{PAPER ELECTROPHORETIC AND INFRA-RED ANALYSIS OF THE URINE IN GARGOYLISM AND MORQUIO-ULLRICH'S DISEASE}

\author{
BY
}

\author{
J. CLAUSEN, H. V. DYGGVE and J. C. MELCHIOR
}

From the University Department of Biochemistry, Copenhagen, the State Institution for Mentally Retarded, 'Andersvange', Slagelse, and the University Clinic of Paediatrics, Rigshospitalet, Copenhagen, Denmark

(RECEIVED FOR PUBLICATION JANUARY 18, 1963)

Urinary excretion of acid mucopolysaccharides of varying composition and amount has been found in a number of rare diseases, mainly affecting the connective tissues. Recently excretion of chondroitin sulphate and hyaluronic acid in the urine of a patient with mastocytosis has been described by Asboe-Hansen and Clausen (1963).

Evidence of the presence of acid mucopolysaccharides in different organs from patients with gargoylism has already been given by Brante (1952) and confirmed by others. Recently inclusions of acid mucopolysaccharides in the lymphocytes of some patients with gargoylism have been described (Mittwoch, 1961 ; Bowman, Mittwoch and Schneiderman, 1962). The occurrence of an abnormal urinary excretion of chondroitin sulphate $B$ and of heparitin sulphate was reported by Dorfman and Lorincz (1957) and by Meyer, Hoffman, Linker, Grumbach and Sampson (1959).

In patients with Morquio-Ullrich's disease, a syndrome placed between gargoylism and MorquioBrailsford's disease, urinary excretion of chondroitin sulphate $B$ and a substance thought to be keratosulphate was found by Zellweger, Ponseti, Pedrini, Stamler and von Noorden (1961), and by Dyggve, Melchior and Clausen (1962).

As considerable research is being conducted in this subject many disorders may be listed as 'mucopolysaccharidosis' in the future: thus the development of diagnostic tools for identification and differentiation between the acid mucopolysaccharides in the urine seems of fundamental importance for the elucidation of the biochemistry of the different forms of 'mucopolysaccharidosis'. In the present publication data will be given of a chemical method combining paper electrophoresis and infra-red analysis for chatacterization of the acid mucopolysaccharides in the urine.

\section{Case Reports}

The case reports of three siblings (J.J., H.J. and L.J.) with Morquio-Ullrich's disease have been published in detail previously (Dyggve et al., 1962). The major findings were mental retardation, dwarfism, skeletal changes and an abnormal urinary excretion of acid mucopolysaccharides. The similarities and differences between this disorder and gargoylism were discussed with regard to the clinical picture and to some extent to the abnormal biochemical findings. The further biochemical aspects will be compared with the findings in the case report of a boy with gargoylism.

Boy, K.S. (born September 15, 1949)

Family History. The father is a healthy man but unfortunately no information is available about his family. The parents were divorced when our patient was 6 years old. The mother is mentally and physically normal; she had had repeated attacks of salpingitis before the birth of our patient. In her family a number of abnormalities are present: the grandmother's sister has epilepsy; a cousin of the grandmother has two children who are deaf-mutes; a cousin of the mother has cheilognathopalatoschisis, and an aunt has a goitre; the grandfather died at 34 years from a stroke. Our patient has a 3-year-old younger brother who is blind in one eye because of a congenital defect involving all the layers. There are no known cases of gargoylism in the family.

The pregnancy was complicated by vomiting, pyelitis and vaginal bleeding during the third month and the mother was confined to bed for one month. During the last few days of pregnancy slight proteinuria and hypertension occurred and delivery was induced by a moderate dose of quinine, but was otherwise uneventful. The infant weighed $3,500 \mathrm{~g}$. and was $53 \mathrm{~cm}$. in length; the head circumference was $36 \mathrm{~cm}$. The Wassermann reaction of the mother was negative.

The neonatal period was uneventful. At the age of 10 months he had a left-sided inguinal herniotomy at the University Clinic of Paediatrics, Rigshospitalet, and it 


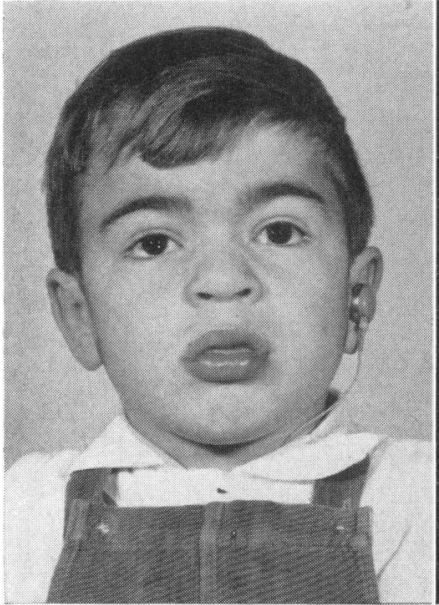

FIG. 1.

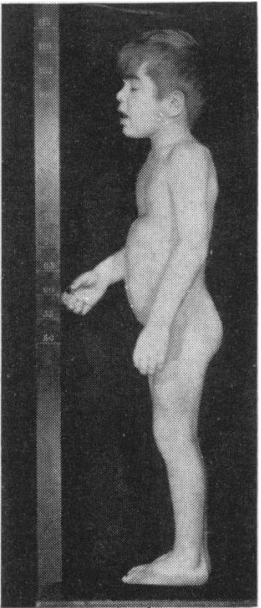

FIG, 2 .

FIG. 1.-K.S., 5 years and 3 months old. Note the thickened lips, the broad nose and the hearing aid.

Fig. 2.-Taken at the same time as Fig. 1. Note the short extremities and the coarse hands, as well as the lumbar lordosis.

was noted that his structure was coarse. He walked unsupported when 13 months old but did not begin to talk until the age of 3 years. In the following years he made little progress in talking, and he suffered from repeated episodes of infection and diarrhoea.

From the age of 3 years he became more and more aggressive in his behaviour and increasingly deaf, and for this reason he was admitted to the University Clinic of Paediatrics at the age of 5 years. A diagnosis of gargoylism was made on the clinical appearance (Figs. 1 and 2), and the radiological findings revealed thickening and shortening of the bones of the extremities. His hearing was much impaired. Despite the use of a hearing aid and psychiatric support his mental development stopped, and at the age of 7 years he was transferred to a State Institution for the Mentally Retarded. From that age a mental deterioration was observed, and he lost his ability to talk and also lost bladder and bowel control.

At the age of 13 years he is completely helpless, unable to talk and makes only few movements. A year ago he could participate in walking, but now this is almost impossible because of increasing dyspnoea. His heart was enlarged at the age of 5 , but lately this has become more marked; there is a murmur and abnormal cardiographic findings. His facial expression is duller than before (Fig. 3). A typical short neck and coarse hands with extension defects of the finger joints can be seen (Fig. 4).

His height is $127 \mathrm{~cm}$. and he has only grown $4 \mathrm{~cm}$. in two years. Repeated eye examinations have shown no corneal opacities. No Reilly granulations or vacuoles have been found in the leucocytes. Serum lipids, serum proteins and protein-bound iodine are normal. Urinary excretion of 17-ketosteroids is normal.

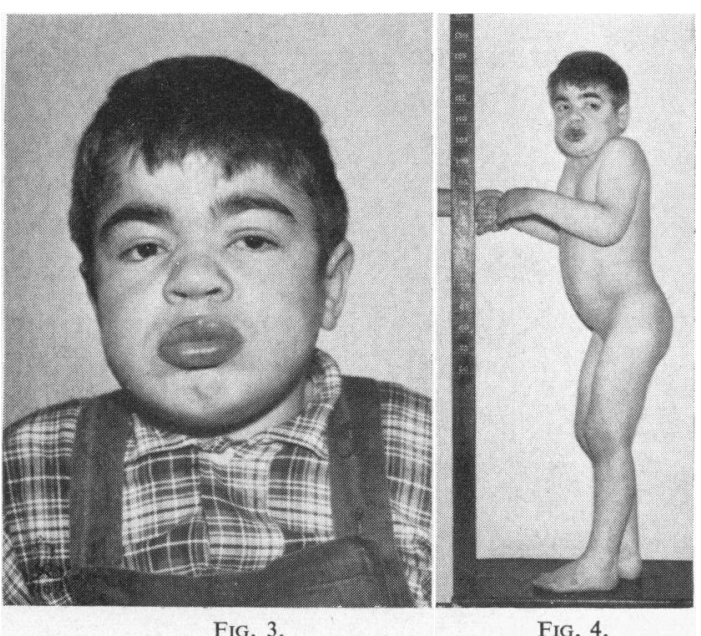

FIG. 3.-K.S., now 13 years old. The facial expression is duller and the features more marked than before.

Fig. 4.-Same as Fig. 3. Note the extension defects of the fingers and the short neck.

An electroencephalogram in 1953 showed some slow activity; in 1957 and 1962 there were moderate numbers of slow waves most pronounced in the left frontal region. Pneumoencephalogram when 5 years old revealed a slight symmetrical ventricular dilatation with an Evans ratio of 0.35 . The width of the third ventricle was $7 \mathrm{~mm}$.

Radiological examination of the skull showed thickening of the bones, and the same was seen in the long bones of the extremities. There were no irregularities of the iliac crest as described in our cases of Morquio-Ullrich's disease (Dyggve et al., 1962). The hands and the spine show moderate, but typical changes (Figs. 5 and 6). The spinal fluid contained $44 \mathrm{mg} . / 100 \mathrm{ml}$. protein and no abnormal cells.

\section{Methods for Determination of Acid Mucopolysaccharides}

Paper electrophoretic demonstration of acid mucopolysaccharides stained with alcian blue or mucicarmine was performed as described by Clausen and Rosenkast (1962) and used by Dyggve et al. (1962). In addition to paper electrophoretic investigations in 'veronal' buffer at $p H$ $8 \cdot 6$, ionic strength $\mu=0.05 \mathrm{M}$, this examination was also performed at $p \mathrm{H} 2 \cdot 8$, ionic strength $\mu=0 \cdot 2 \mathrm{M}$ in a lithium chloride solution (Foster and Pearce, 1961). The urines were filtered through a Whatman no. 1 filter and concentrated by vacuum dialysis before paper electrophoresis.

Infra-red Analysis. Before the analysis urinary acid mucopolysaccharides were isolated by two methods: one based upon the principle described by Clausen and Rosenkast (1962) used double enzymatic digestion, with trypsin and pepsin, of the proteins in a 24-hour urine 

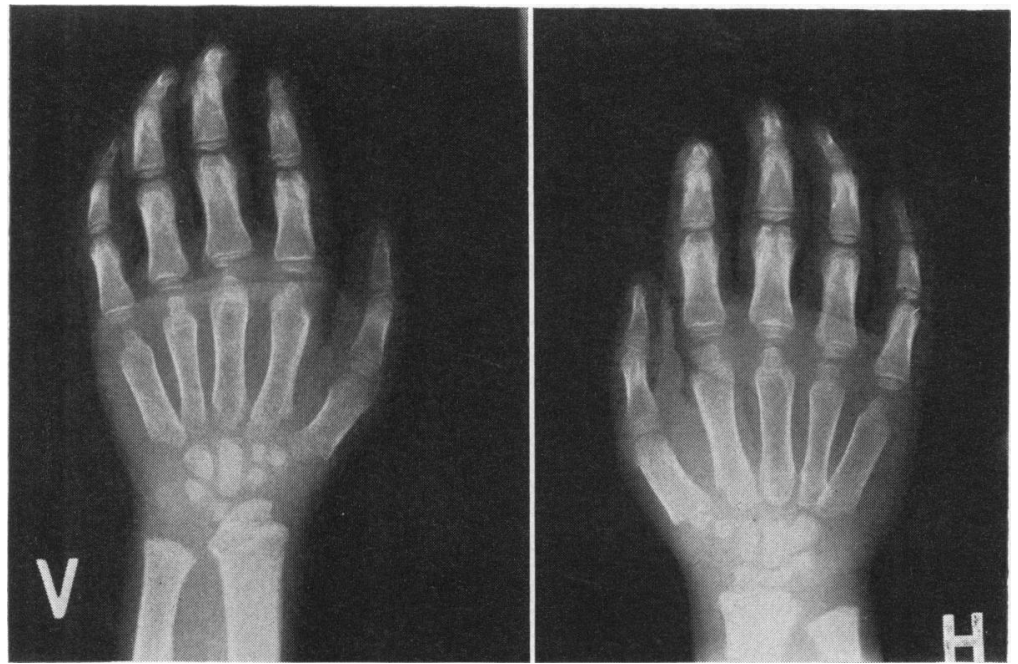

FIG. 5.-Radiograph of the hands at the age of 13 years. The fingers are short and broad; the skeletal bone age somewhat retarded

sample. The acid mucopolysaccharides remaining in the urine after dialysis were isolated by stepwise precipitation with ethanol containing $2 \% \mathrm{CaCl}_{2}$ (Zachariae and Dyrbye, 1959). The precipitates were dialysed against running tap water for two days and for 24 hours against saline, and finally isolated from this solution as a sodium

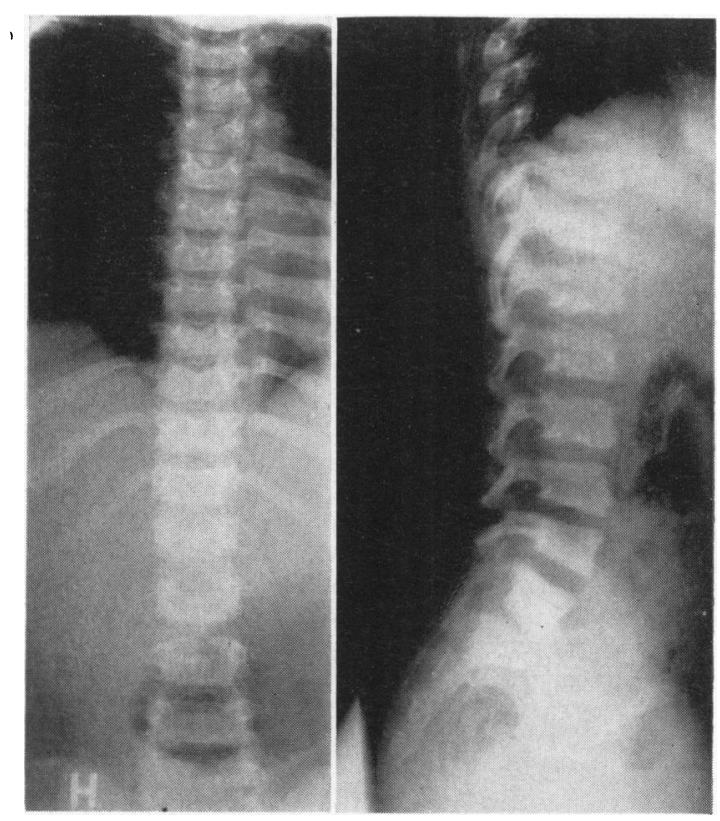

Fig. 6.-Radiograph of the spine at the same age as Figs. 3-5. Only slight changes are found in the lumbar vertebrae with flattening and some irregularities. salt by evaporation on watch-glass, heated from below, by steam. They were dried in a vacuum extractor over silica gel.

Another method for isolation of the acid mucopolysaccharides was to submit concentrated urine to a preparative electrophoresis in 'pevicon' 870 (polyvinylpyrrolidone) suspended in a 'veronal' buffer $p H=8 \cdot 6$, ionic strength $\mu=0.05 \mathrm{M}$ (Müller-Eberhard, 1960). Because of the higher migration rate of the acid mucopolysaccharides as compared to the proteins it is possible after eight to 16 hours' running time to isolate the acid mucopolysaccharides by extraction from sections of the pre-albumin area obtained by cutting the electrophoretic medium every $1 \mathrm{~cm}$. Paper electrophoretic control of the concentrated extracts would reveal which fraction contained acid mucopolysaccharides as described above.

The infra-red analysis was performed in a Unicam SP 200 infra-red spectrophotometer with rock salt prisms, using the potassium bromide disk technique (Schiedt and Reinwein, 1952). From 1 to $5 \mathrm{mg}$. dried acid mucopolysaccharides were mixed with $100 \mathrm{mg}$. potassium bromide and pressed to pellets (Clausen and Andersen, 1963; Clausen and Hansen, 1963; AsboeHansen and Clausen, 1963). The infra-red analysis was based upon comparison with spectra obtained from standard preparations of hyaluronic acid, chondroitin sulphate and heparin and on data on group frequencies collected by Jones and Sandorfy (1956) and by Bellamy (1958).

\section{Results}

Paper electrophoretic investigations of the urines revealed some differences between the patients with Morquio-Ullrich's disease and the patient with gargoylism (Figs. 7 and 8). In the patients with 


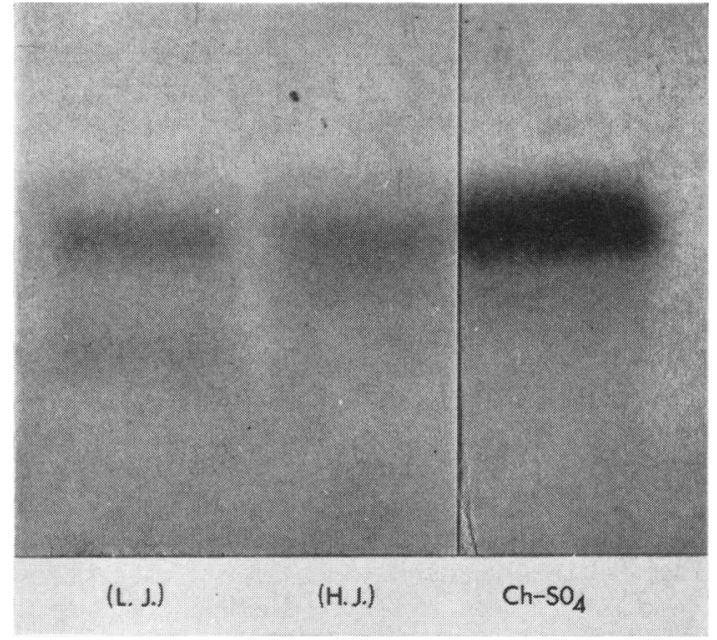

FIG. 7.-The paper electrophoretic pattern of acid mucopolysaccharides in urine concentrated 100 times from two patients with Morquio-Ullrich's disease (L.J. and H.J.). The electrophoresis was performed in a $0.2 \mathrm{M} \mathrm{LiCl}$ solution ( $p \mathrm{H} 2.8)$. The findings are correlated with those of the chondroitin sulphate marker (staining with alcian blue).

In the urine from Case L.J. two distinct fractions of acid mucopolysaccharide can be seen. The faster corresponds in mobility to the chondroitin sulphate marker; the slower has a mobility between that of unpolymerized hyaluronic acid, which will be situated at the application line most cathodically, and that of the chondroitin sulphate marker (see also Fig. 11). In the urine from case H.J. a similar picture can be seen; only the cathode fraction seems to be very weak.

Morquio-Ullrich's disease (H.J. and L.J.) (Fig. 7) two fractions of acid mucopolysaccharides were found: the main fraction having a mobility as the chondroitin sulphate, the minor fraction a mobility somewhat slower but faster than unaltered hyaluronic acid. These findings were described in detail by Dyggve et al. (1962). The urine from the patient with gargoylism (K.S.) showed an enormous diffuse fraction of acid mucopolysaccharides with a mobility similar to chondroitin sulphate, but from this area the acid mucopolysaccharide zone extended anodically towards the area of the heparin marker in the $\mathrm{LiCl}$ buffer (Fig. 8).

Infra-red analysis of the urine from the patient with gargoylism (K.S.) using both methods for isolation of the acid mucopolysaccharides revealed identical results. Only one fraction could be isolated by alcohol precipitation as well as by cutting of sections from the pre-albumin area in the 'pevicon' electrophoresis. Figs. 9 and 10 show that only one fraction is seen with the following absorption frequencies: $3,400,2,900,1,620,1,560,1,460$, $1,420,1,320,1,250,1,150,1,100-1,000,930,880$, 820,780 and $720 \mathrm{~cm} \cdot{ }^{-1}$.

In the urine from two of the siblings with Morquio-

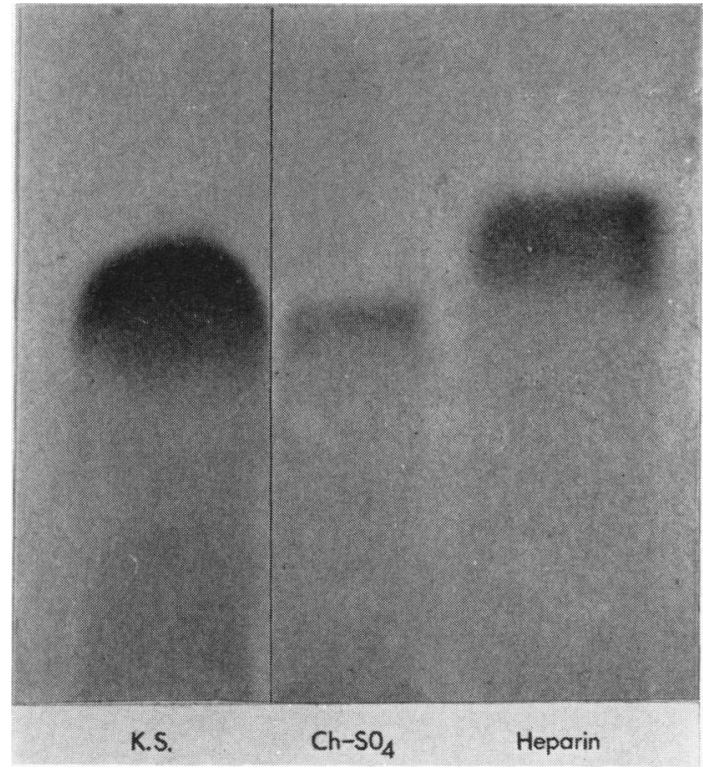

FIG. 8.-The paper electrophoretic pattern of acid mucopolysaccharides in urine concentrated 100 times from a patient with gargoylism (K.S.). The electrophoresis was performed in a $0.2 \mathrm{M}$ $\mathrm{LiCl}$ solution $(\mathrm{pH} 2 \cdot 8)$. The findings are correlated with markers of chondroitin sulphate $(\mathrm{A}+\mathrm{B})$ and heparin (staining with alcian blue). Only one fraction of acid mucopolysaccharides with a similar mobility to the chondroitin sulphate marker can be seen.

Ullrich's disease (H.J. and L.J.) two fractions of acid mucopolysaccharides were isolated by ethanol fractionation. This is in agreement with the fact that two fractions were visualized in the concentrated urine by staining the paper electrophoretic pattern with alcian blue. The major fraction, flocculating between $18-25 \%$ ethanol, revealed an electrophoretic homogeneous fraction with a mobility similar to the chondroitin sulphate marker. The infra-red spectrum showed absorption frequencies at $3,400,2,900,1,620,1,560,1,460,1,420$, $1,320,1,250,1,100-1,000,930,880,820,780$ and $720 \mathrm{~cm}^{-1}$. The minor fraction was not homogeneous on paper as it revealed two bands one with the same mobility as the chondroitin sulphate marker, and one with a somewhat slower mobility, which was faster than the unaltered hyaluronic acid marker which does not move in paper electrophoresis at $p \mathrm{H} 2 \cdot 8(\mathrm{LiCl}$ solution at ionic strength $\mu=0.2 \mathrm{M}$ ). Thus the electrophoretic pattern was similar to that obtained by heating $0.5 \%$ hyaluronic acid from below by steam. Untreated hyaluronic acid, $0.5 \%$, just dissolved in saline reveals a nonmigrating fraction on paper electrophoresis performed in $\mathrm{LiCl}$ solution at $p \mathrm{H} 2 \cdot 8$ (ionic strength 


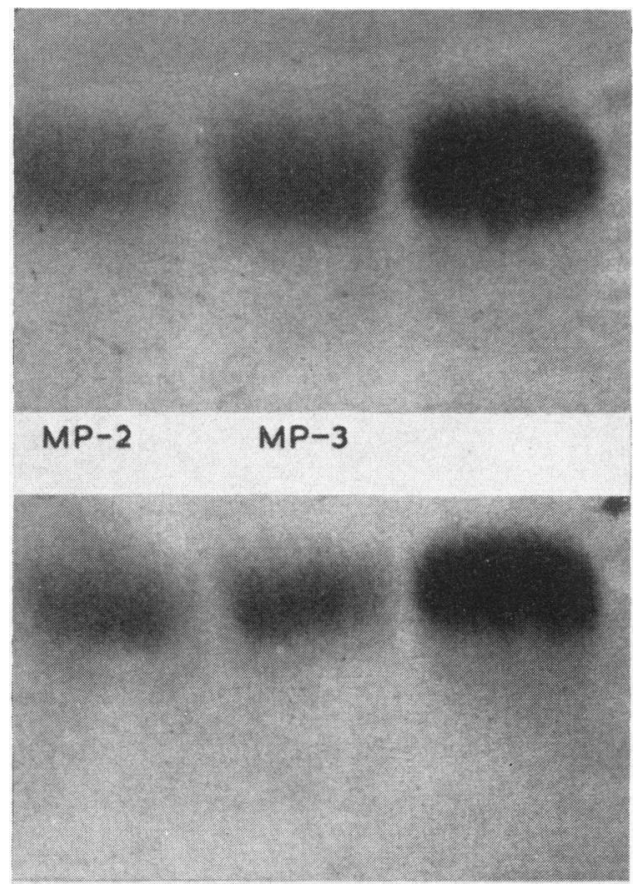

$\mathrm{MP}-3 \quad \mathrm{MP}-4$

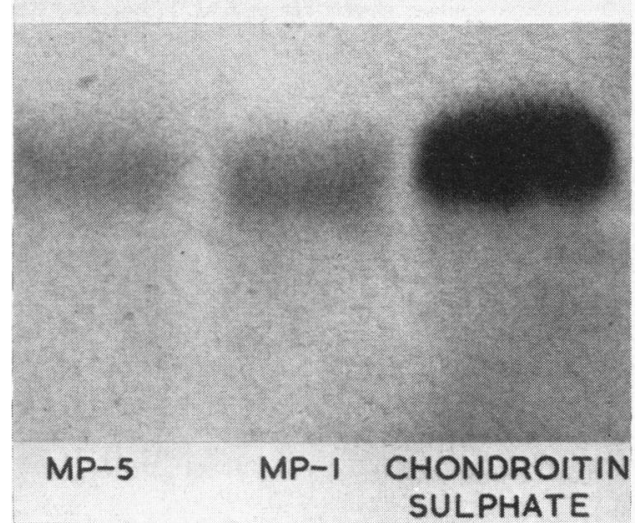

Fig. 9.-Five fracticns of acid mucopolysaccharides (MP) with identical mobility obtained by preparative electrophoresis in a 'pevicon' 870 medium wetted with a 'veronal' buffer $(p \mathrm{H} 8.6$ ionic strength $\mu=0.05 \mathrm{M})$. The $\mathrm{r}$ re-albumin area was cut out every $1 \mathrm{~cm}$. and every section was extracted with saline and concentrated by vacuum dialysis. The extracts from two neighbouring sections were pooled and parer electrophoretic control for the acid mucopolysaccharide content was dene (veronal buffer $p \mathrm{H} 8 \cdot 6$, ionic strength $\mu=0.05 \mathrm{M}$ ) (staining with alcian blue).

Only one fraction with a mobility similar to chondroitin sulphate could be obtained.

$u=0.2 \mathrm{M})$. However, if the hyaluronic acid (dissolved in saline with or without the presence of $\mathrm{Fe}^{+++}$ions, $0.5 \mathrm{M}$ ) is heated by steam from below for about three-quarters of an hour until dried, and then redissolved and studied by paper electrophoresis, two migrating fractions stainable by alcian blue can be found. The one with the fastest migration has a mobility corresponding to the chondroitin sulphate marker. The other fraction migrated faster than untreated hyaluronic acid but slower than the chondroitin sulphate marker (Fig. 11). Thus the fraction from the urines of H.J. and L.J. precipitating between $40-75 \%$ and between $50-75 \%$ ethanol respectively has an electrophoretic pattern corresponding to the pattern of heated hyaluronic acid. The infra-red analysis revealed absorption frequencies at $3,400,2,900$, $1,650,1,480-1,420,1,200-1,000 \mathrm{~cm} .^{-1}$ similar to the findings of untreated hyaluronic acid. Furthermore, in the finger-print area, i.e. the area below $1,000 \mathrm{~cm} .^{-1}$, where unaltered hyaluronic acid does not reveal any distinct absorption bands, one or two bands are seen for every fraction mentioned above at 880 and/or $820 \mathrm{~cm}^{-1}$ (Figs. 12 and 13). The intensities of these two absorption bands seem to some extent to vary depending on the duration of heating and the presence of other ions (Clausen, 1963).

\section{Discussion}

In a previous paper we discussed the differential diagnostic problems of the syndrome called MorquioUllrich's disease and we reported on our preliminary findings of an abnormal excretion of acid mucopolysaccharides in the urine. In the three siblings (J.J., H.J. and L.J.) paper electrophoretic investigations revealed two fractions stainable with alcian blue or mucicarmine. It was shown that the main fraction corresponded to chondroitin sulphate $\mathbf{A}+\mathbf{B}$, whereas the minor fraction had a mobility placing it in the zone between the hyaluronic acid and the chondroitin sulphate markers. Whether this minor fraction was keratosulphate as suggested by Zellweger et al. (1961) was considered, but this could not be proved or disproved, because keratosulphate could not be identified by this method (Dyggve et al., 1962).

The pattern of acid mucopolysaccharides from the urine of the patient with gargoylism (K.S.) was different. Only one fraction was found corresponding to chondroitin sulphate extending somewhat anodically.

The paper electrophoretic investigations give valuable information on the mobilities of the fractions found, but do not give information on the chemical groups constituting the acid mucopolysaccharides. However, a correct identification of the different acid mucopolysaccharides is only 


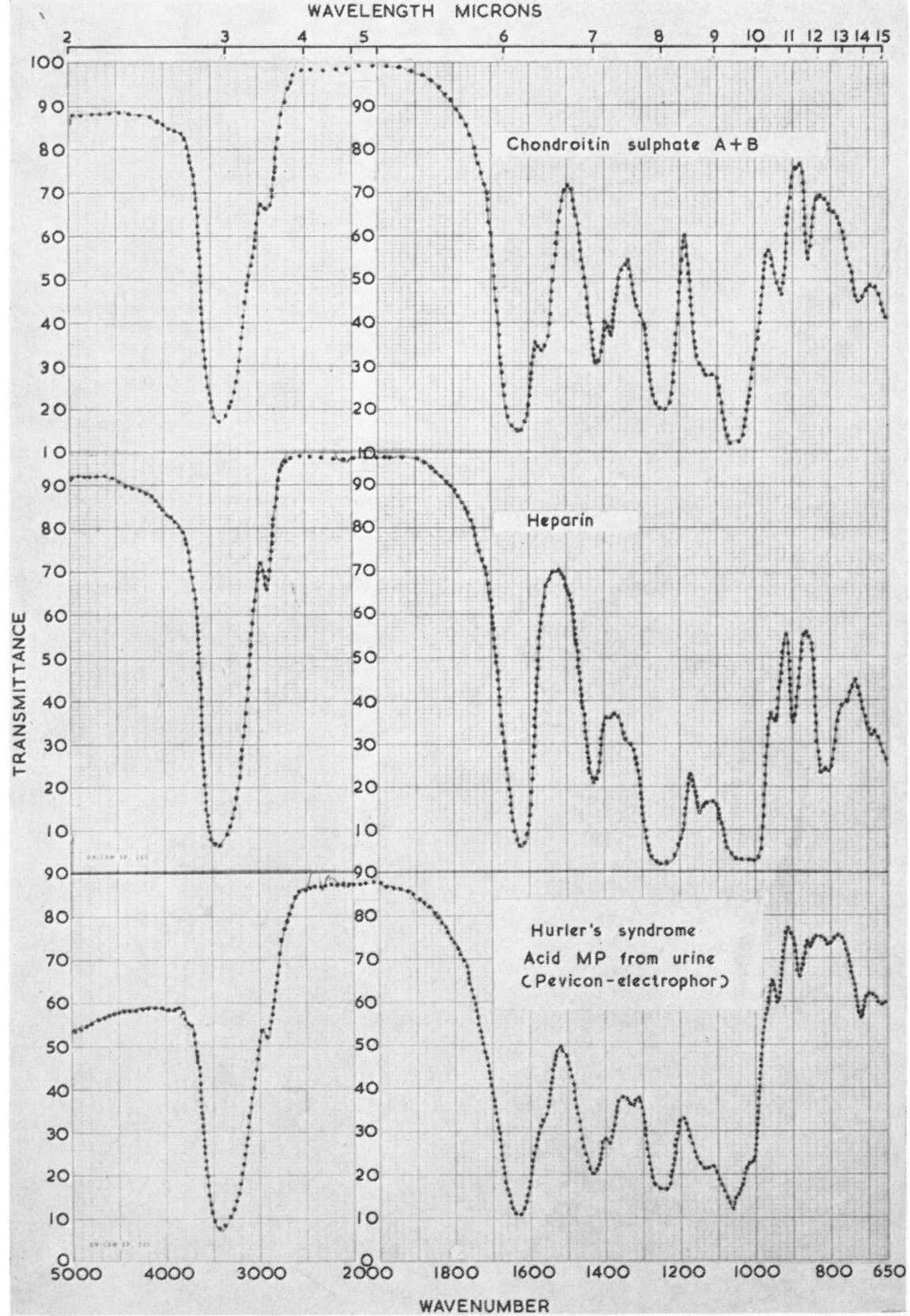

FIG. 10.- Infra-red spectrograms of standard preparations of heparin and chondroitin sulphate correlated to the findings of an electrophoretic homogeneous fraction of acid mucopolysaccharides occurring in the urine from a case of gargoylism (K.S.). This fraction was isolated by preparative electrophoresis in a 'pevicon' 870 medium ('veronal' buffer $p \mathrm{H} 8 \cdot 6$, ionic strength $\mu=0 \cdot 05 \mathrm{M}$ ). The acid mucopolysaccharides were analysed after the $\mathrm{KBr}$ disk technique $(4 \mathrm{mg}$. acid $\mathrm{MP} / 100 \mathrm{mg}$. $\mathrm{KBr}$ ). The acid mucopolysaccharide fraction from $\mathrm{K} . \mathrm{S}$. reveals absorption bands similar to chondroitin sulphate. 


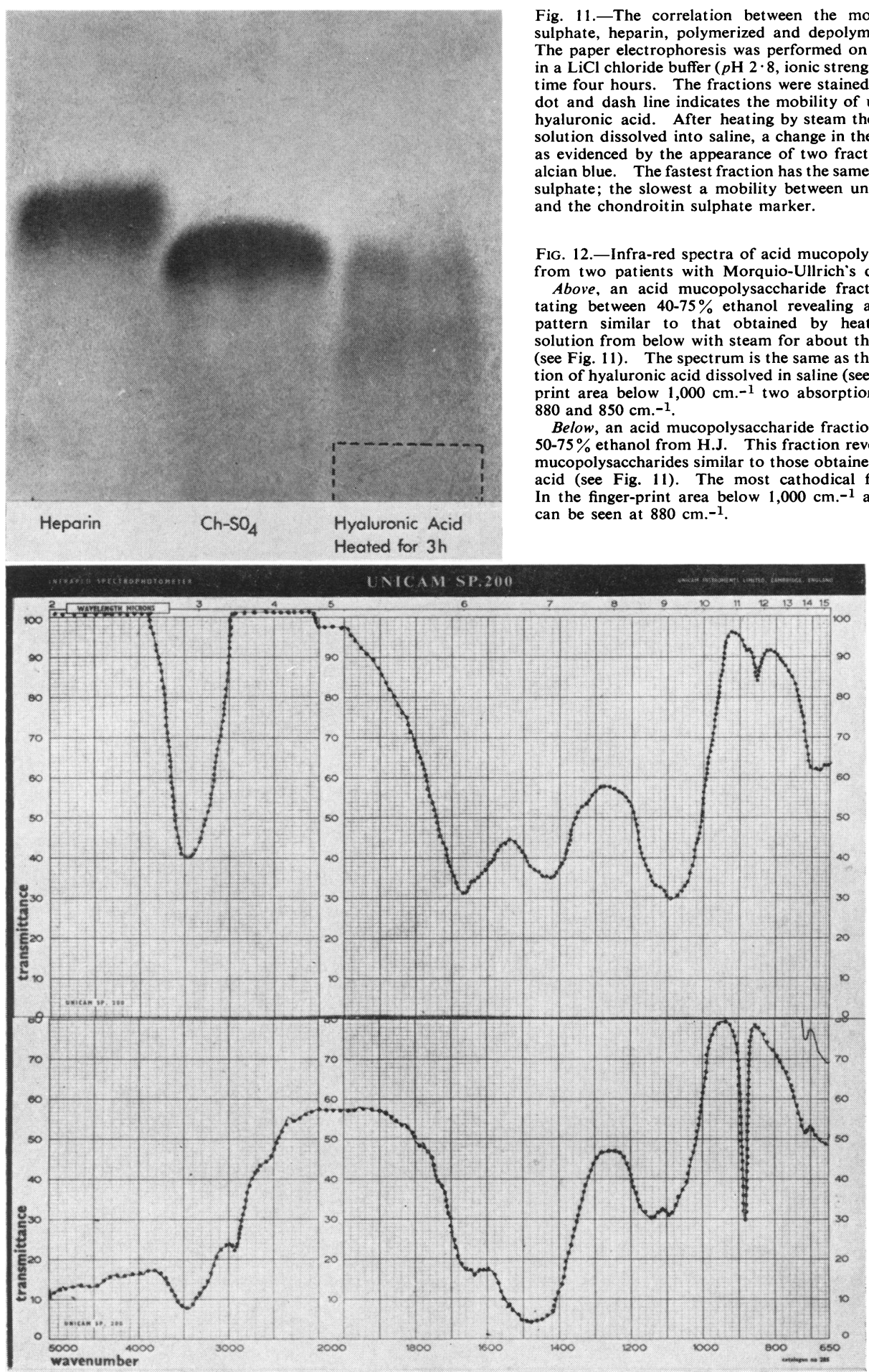

FIG. 12. 


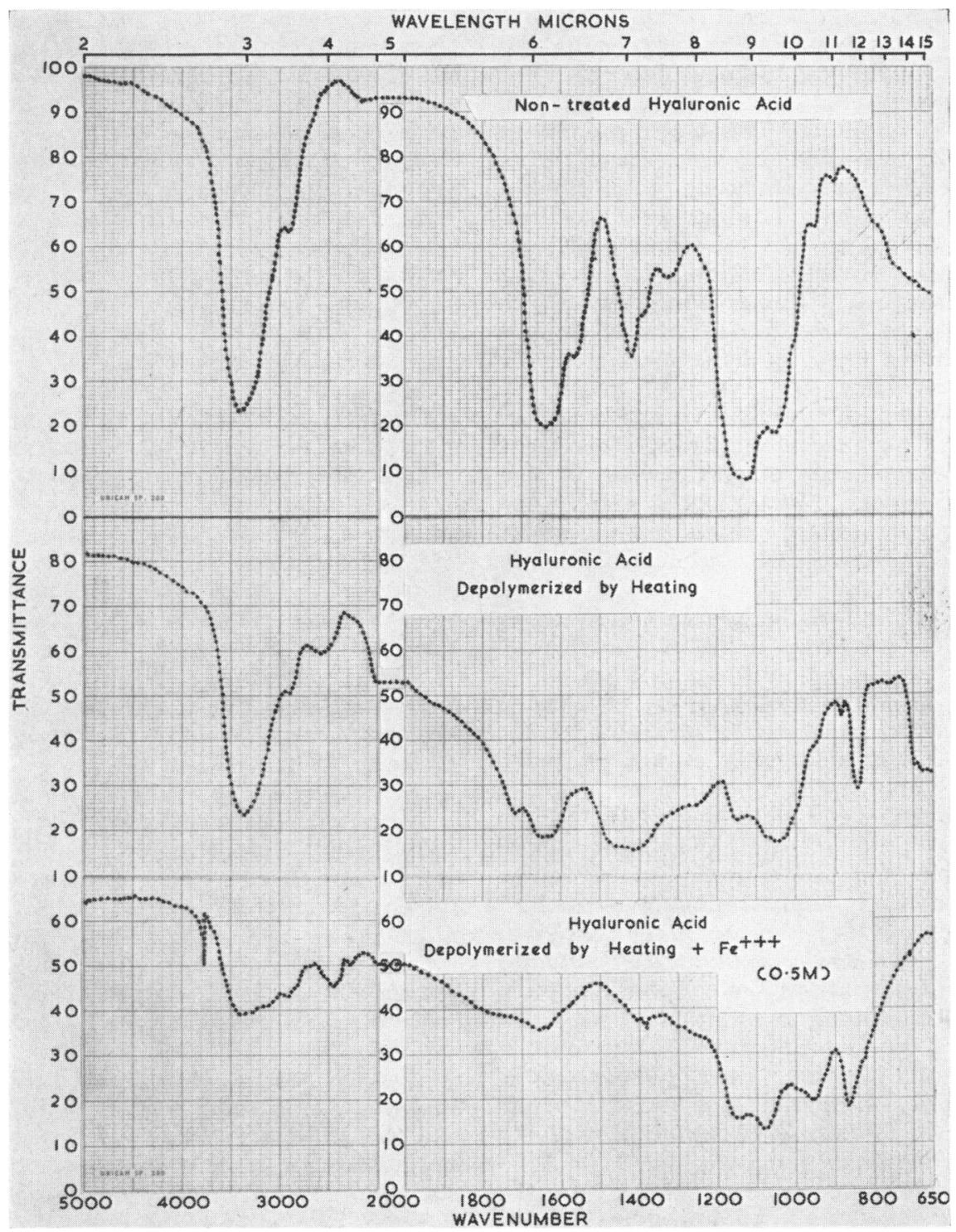

FIG. 13.-Infra-red analysis of untreated and treated hyaluronic acid. Above, the infra-red spectrum of untreated hyaluronic acid, which only reveals one, non-migrating fraction in paper electrophoresis at $p \mathrm{H} 2 \cdot 8(\mathrm{LiCl}$ solution). Absorption bands can be seen at: $3,400,2,900$, $1,650,1,560,1,450,1,4201,380,1,320$, a broad band with two peaks at: 1,200-1,000, and no distinct band in the finger-print area (the area below $\left.1,000 \mathrm{~cm} \cdot{ }^{-1}\right)$.

Middle, two spectra obtained of treated hyaluronic acid. By evaporation of a $0.5 \%$ hyaluronic acid in saline with steam from below for about three-quarters of an hour (until dried) some weakening of the absorption bands in the area above $1,000 \mathrm{~cm} .^{-1}$ (the area of the group frequencies) can be seen. Below $1,000 \mathrm{~cm} .^{-1}$, in the finger-print area, two distinct absorption bands at 880 and $850 \mathrm{~cm} . .^{-1}$ are seen.

Below, by further treatment with $0.5 \mathrm{M} \mathrm{Fe}+++$ ions in hyaluronic acid solution during the evaporation procedure even weaker and broader absorption bands above $1,000 \mathrm{~cm} \cdot .^{-1}$ can be seen. In the finger-print area there are two broad bands at 950 and $870-880 \mathrm{~cm} .-1$. 
possible if information can be obtained about the chemical groups included in these complex metabolic products. The conventional chemical procedure for estimation of carboxyl-, hydroxyl-, and aldehyde groups as well as estimation of sulphuric acid and of the type of hexose and uronic acid seem to be time consuming and often unspecific (Gibian, 1959). They are, therefore, not suitable for routine analysis.

The infra-red analysis, however, seems to overcome these difficulties. As mentioned earlier the necessary isolation procedure for purification of the single acid mucopolysaccharide is relatively easy to perform either as preparative electrophoresis in a 'pevicon' medium (polyvinylpyrrolidone) or by the more time-consuming procedure of proteolytic digestion followed by stepwise ethanol precipitation. Every fraction can be controlled within four hours by paper electrophoresis of their content of acid mucopolysaccharides. The analysis by infra-red spectroscopy of the isolated acid mucopolysaccharide by the potassium bromide disk technique takes only 15 minutes.

The interpretation of the spectra usually seems to be simple. All the acid mucopolysaccharides reveal identical absorption frequencies mainly in the area above $1,000 \mathrm{~cm} \cdot{ }^{-1}$. Thus the $3,400 \mathrm{~cm} . .^{-1}$ can be explained by stretching vibrations of the bound $\mathrm{OH}$-groups and of free as well as bound $\mathrm{NH}$-groups. The $2,900 \mathrm{~cm} \cdot .^{-1}$ band can originate from the stretching vibrations of the $\mathrm{CH}_{2}{ }^{-}$or the $\mathrm{CH}_{3}$-groups. The band $1,660-1,640 \mathrm{~cm} .^{-1}$ can be explained by the $\mathrm{C}=\mathrm{O}$ stretching vibration, e.g. in the carboxyl groups, but monosubstituted amide groups can also give rise to an absorption at $1,650 \mathrm{~cm} .^{-1}$ as well as at $1,560 \mathrm{~cm}^{-1}$. Free amide groups will absorb at $1,560 \mathrm{~cm} .^{-1}$ as indicated in Fig. 10. Most probably the $1,560 \mathrm{~cm} .^{-1}$ band can be attributed to $\mathrm{N}$-acetyl groups. The bands at $1,420 \mathrm{~cm} .^{-1}$ and $1,385 \mathrm{~cm} .^{-1}$ can be caused by the presence of $\mathrm{CH}_{3}$-CO (bending in plane, scissor), and the band at $1,320 \mathrm{~cm} .^{-1}$ can be attributed to the $\mathrm{OH}$-bending in plane.

The great absorption band at about 1,040-1,160 $\mathrm{cm} .^{-1}$ can also be seen in all polysaccharides and can be explained by the stretching vibrations of -CC- and of -CO- groups and by $\mathrm{CN}$ stretching vibrations.

However, hyaluronic acid, which is composed in polymerized form of a macromolecule with glucuronic acid in beta-1,3-glycoside bound with $\mathrm{N}$ acetyl-D-glucosamin as repeating unit, does not possess any characteristic feature in the finger-print area (the area below $1,000 \mathrm{~cm} .^{-1}$ ). However, this is the case with the sulphate-containing acid mucopolysaccharides (heparin, chondroitin sulphate $(\mathrm{A}$,
$B$ and C) and keratosulphate). But the sulphate $\mathbf{S}=\mathbf{O}$ stretching vibration is also seen as the characteristic absorption band at $1,240 \mathrm{~cm} .^{-1}$. The $1,240 \mathrm{~cm} .^{-1}$ absorption band is a group frequency and has nearly the same localization in all the sulphate-containing acid mucopolysaccharides. This characteristic absorption band thus obeys the law of group frequencies (Jones and Sandorfy, 1956). On the other hand the finger-print area below $1,000 \mathrm{~cm} .^{-1}$ gives absorption bands characteristic for every acid mucopolysaccharide (see the Table) (Orr, Harris and Sylvén, 1952; Orr, 1954; Bernardi, Happey and Naylor, 1957; Mathews, 1958; Hoffman, Linker and Meyer, 1958; Gibian, 1959). It must be mentioned that some variations occur in the recorded values for the absorption bands taken from the literature. Furthermore, it has to be stressed that the infra-red spectrum recorded as typical of hyaluronic acid does not seem to be constant as demonstrated in the present communication. Thus heating with steam for about threequarters of an hour will cause changes which can be visualized in infra-red spectroscopy (Fig. 13). These changes occur when the hyaluronic acid is dissolved in saline but the process seems to be accelerated by iron ions. The changes even occur on standing for 14 days at room temperature (Clausen, 1963).

The changes in the hyaluronic acid are characterized by the appearance of one or two characteristic absorption bands at 880 and $850 \mathrm{~cm} .^{-1}$. In paper electrophoresis these changes are reflected in the appearance of two fractions which stain with alcian blue or with mucicarmine, one just cathodically to the chondroitin sulphate marker and one fraction with a similar mobility. This can be seen both at $p \mathrm{H} 8 \cdot 6$, and apparently even better at $p \mathrm{H} 2 \cdot 8$ (lithium chloride solution), because at $p \mathrm{H} 2 \cdot 8$ the non-treated hyaluronic acid does not migrate. The changes occurring in hyaluronic acid, visualized both by infra-red analysis and by paper electrophoresis, seem difficult to explain. But the increased mobility of the two fractions obtained by the treatment seems to indicate an increase in the acid dissociation constant of the carboxyl group occurring in glucuronic acid. At $p \mathrm{H} 2 \cdot 8$ the non-treated hyaluronic acid does not migrate because the carboxyl group is not dissociated. On the other hand the sulphate-containing acid mucopolysaccharides migrate on account of the great acidity of the sulphuric acid group, still dissociated at $p \mathrm{H} 2 \cdot 8$ (Clausen, 1963).

The methods and results discussed above are of fundamental significance for the identification of the different forms of mucopolysaccharidosis. Thus, 
TABLE

FINGER-PRINT AREA (cm.-1)

\begin{tabular}{|c|c|c|c|c|c|c|c|c|c|}
\hline $\begin{array}{l}\text { Heparin } \\
\text { Chondroitin sulphate A } \\
\text { Chondroitin sulphate B } \\
\text { Chondroitin sulphate C } \\
\text { 'Changed' hyaluronic acid }\end{array}$ & $\begin{array}{l}\cdots \\
\cdots \\
\cdots \\
\cdots\end{array}$ & $\begin{array}{l}\cdots \\
\cdots \\
\cdots \\
\cdots\end{array}$ & \begin{tabular}{l|}
$\cdots$ \\
$\cdots$ \\
$\cdots$ \\
$\cdots$
\end{tabular} & $\begin{array}{r}980 \\
1,000\end{array}$ & $\begin{array}{l}920 \\
920 \\
928\end{array}$ & $\begin{array}{l}880 \\
852 \\
855 \\
820 \\
880\end{array}$ & $\begin{array}{l}800 \\
840 \\
775 \\
850\end{array}$ & $\left.\right|_{(780)}$ & $\begin{array}{l}700 \\
725 \\
712\end{array}$ \\
\hline
\end{tabular}

on one hand paper electrophoresis of urine concentrated 100 times reveals a pathological excretion of acid mucopolysaccharides as already described (Dyggve et al., 1962), whereas normal urine concentrated 100 times permits no staining for acid mucopolysaccharides (Heremans, Vaerman and Heremans, 1960). On the other hand it is not possible to be sure of the differentiation by paper electrophoresis between chemically altered hyaluronic acid and chondroitin sulphate as stated above. Heparin can easily be differentiated from the two other acid mucopolysaccharides because of its high migration rate especially at $p \mathrm{H} 2 \cdot 8$ using lithium chloride (Foster and Pearce, 1961). Infra-red analysis, however, has the ability to reveal the differences between unchanged and changed hyaluronic acid and chondroitin sulphate.

Thus, in the urine of our patient with gargoylism it was only possible to isolate one single fraction of acid mucopolysaccharide migrating homogeneously both before and after the isolation procedure both by preparative electrophoresis of concentrated urine and by proteolytic digestion of the proteins in the urine followed by ethanol fractionation. This fraction shows absorption bands in the fingerprint area below $1,000 \mathrm{~cm} .{ }^{-1}$ at $930,880,820,780$ and $720 \mathrm{~cm} .^{-1}$, similar to chondroitin sulphate B.

On the other hand two fractions were isolated in the urine from the three siblings with MorquioUllrich's disease; one flocculating at $18-25 \%$ ethanol with an infra-red spectrum identical with chondroitin sulphate $B$ and one flocculating from $40-50-75 \%$ ethanol. The last mentioned fraction corresponded in mobility on paper to chemically altered hyaluronic acid giving rise to the one or two characteristic absorption bands at 880 and at 850 $\mathrm{cm} .{ }^{-1}$ in the infra-red spectrum. By graduated alcohol fractionation in the intervals $40-50$ and $50-75 \%$ ethanol, the internal proportions between the two specific absorption bands at 880 and $820 \mathrm{~cm} .^{-1}$ in altered hyaluronic acid were changed, probably indicating that the hyaluronic acid in the new form consisted of a mixture of two fractions with mobilities similar to chondroitin sulphate and somewhat slower than that.

Since the infra-red analysis is relatively easy to perform and since the preparatory steps for isolation of the acid mucopolysaccharides can be performed in one or two days, it is suggested that this method be used for differentiating between the acid mucopolysaccharides.

It has not been possible to demonstrate in these cases any urinary excretion of heparitin sulphate as described by Meyer et al. (1959). Probably no heparitin sulphate was excreted or the amount was too small for the isolation procedures used. In Morquio-Ullrich's disease on the other hand Zellweger et al. (1961) demonstrated besides chondroitin sulphate B a urinary excretion of possible keratosulphate. This latter compound was not found in our investigations, but hyaluronic acid, probably in an altered form, was found. This shows, as already suggested in our previous communication, that the three siblings under investigation suffer from a special form of mucopolysaccharidosis.

Concerning the chemical form in which the hyaluronic acid was found in the urine from these children, the altered constitution of hyaluronic acid could be caused by the isolation procedures, but it cannot be denied that it could be caused by urinary alterations or by a special enzymatic inborn error of metabolism.

\section{Summary}

Continued studies of the abnormal urinary excretion of acid mucopolysaccharides in three siblings with Morquio-Ullrich's disease and one child with gargoylism are reported. A new combined procedure making use of paper electrophoretic demonstration of urinary acid mucopolysaccharides followed by isolation of these and identification of the chemical constitution of each by infra-red spectroscopy is described. The isolation of the urinary acid mucopolysaccharides can be performed either by preparative electrophoresis in 'pevicon' 870 or by proteolytic digestion of proteins followed by ethanol precipitation and stepwise paper electrophoresis.

These examinations showed in two of the three siblings with Morquio-Ullrich's disease that chondroitin sulphate $\mathbf{B}$ and altered hyaluronic acid were 
excreted in the urine, but not keratosulphate. In our patient with gargoylism excretion of chondroitin sulphate B was confirmed but no excretion of heparin could be demonstrated.

Our thanks are due to Professor Lundquist, the University Department of Biochemistry, to Dr. Bredmose, 'Andersvænge', and to Professor Plum, the University Clinic of Paediatrics, Rigshospitalet, Copenhagen, for their kind interest in this study. The studies have been supported by a PHG Research Grant B-2408 from the National Institute of Neurological Diseases and Blindness, Bethesda, U.S.A. and by grants from the Danish League Against Multiple Sclerosis, Copenhagen, and from the Research Funds for Mental Retardation, Copenhagen, Denmark.

\section{REFERENCES}

Asboe-Hansen, G. and Clausen, J. (1963). Acid mucopolysaccharide in blood serum and urine from a patient with mastocytoma. J. exo. Med. In the press.

Bellamy, L. J. (1958). The Infra-red Spectra of Complex Molecules, 2nd ed. Methuen, London.

Bernardi, G., Happey, F. and Naylor, A. (1957). Mucopolysaccharides from cartilage and nucleus pulposus. Nature saccharides from
(Lond.), 180, 1341.

Bowman, J. E., Mittwoch, U. and Schneiderman, L. J. (1962). Persistence of mucopolysaccharide inclusions in cultures of lymphocytes from patients with gargoylism. ibid., 195, 612 .

Brante, G. (1952). Gargoylism-A mucopolysaccharidosis. Scand. J. clin. Lab. Invest., $4,43$.

Clausen, J. (1963). To be published. and Andersen, V. (1963). Acid mucopolysaccharides in human leucocytes. Clin. chim. Acta., 8, 505. leucocytes. brain. J. Neurochem., 10, 165.

and Rosenkast, P. (1962). Isolation of acid mucopolysaccharides of human brain. ibid., 9,393 .
Dorfman, A. and Lorincz, A. E. (1957). Occurrence of urinary acid mucopolysaccharides in the Hurler syndrome. Proc. nat. Acad. Sci. (Wash.), 43, 443.

Dyggve, H. V., Melchior, J. C. and Clausen, J. (1962). MorquioUllrich's disease; An inborn error of metabolism? Arch. Dis. Childh., 37, 525.

Foster, T. S. and Pearce, R. H. (1961). Zone electrophoresis of acid mucopolysaccharides. Canad. J. Biochem., 39, 1771.

Gibian, H. (1959). Mucopolysaccharide und Mucopolysaccharidasen. Deuticke, Vienna.

Heremans, M. Th., Vaerman, J. P. and Heremans, J. F. (1960). Studies on normal urinary colloids. In Protides of the Biological Fluids. Proc. VII Colloquium, Bruges, 1959, ed. H. Peeters, p. 396. Elsevier, Amsterdam.

Hoffman, P., Linker, A. and Meyer, K. (1958). The acid mucopolysaccharides of connective tissue. III. The sulphate linkage. Biochim. biophys. Acta (Amst.), 30, 185.

Jones, R. N. and Sandorfy, C. (1956). The application of infrared and Raman spectrometry to the elucidation of molecular structure. In Chemical Applications of Spectroscopy, ed. structure. In Chemical Applications of Spectrc
W. West, pp. 247-580. Interscience, New York.

Mathews, M. B. (1958). Isomeric chondroitin sulphates. Nature (Lond.), 181, 421.

Meyer, K., Hoffman, P., Linker, A., Grumbach, M. M. and Sampson, P. (1959). Sulfated mucopolysaccharides of urine and organs in gargoylism (Hurler's syndrome). II. Additional studies. Proc. Soc. exp. Biol. (N.Y.), 102, 587.

Mittwoch, U. (1961). Inclusions of mucopolysaccharide in the lymphocytes of patients with gargoylism. Nature (Lond.) lymphocyte 1315.

Müller-Ėberhard, H. J. (1960). A new supporting medium for preparative electrophoresis. Scand. J. clin. Lab. Invest., 12, 31.

Orr, S. F. D. (1954). Infra-red spectroscopic studies of some polysaccharides. Biochim. biophys. Acta (Amst.), 14, 173.

Harris, R. J. C. and Sylvén, B. (1952). Evidence from infra-red spectroscopy for the composition of certain polysaccharides. Nature (Lond.), 169, 544.

Schiedt, U. and Reinwein, H. (1952), Zur Infrarot-Spektroscopie von Aminosäuren. 1. Mitt.: Eine nene Präparationstechnik zur Infrarot-Spektroscopie von Aminosäuren und anderen polaren Infrarot-Spektroscopie von Aminosä
Verbindungen. Z. Naturf., $7 \mathbf{b}, \mathbf{2 7 0}$.

Zachariae, F. and Dyrbye, M. O. (1959). Methods for isolation and identification of acid mucopolysaccharides in connective tissue. Acta rheum. scand., 5, 190 .

Zellweger, H., Ponseti, I. V., Pedrini, V., Stamler, F. S. and von Noorden, G. K. (1961). Morquio-Ulirich's disease. J. Pediat. 59, 549. 